\title{
Fouling control in a woven fibre microfiltration membrane for water treatment
}

\author{
Martha Noro Chollom ${ }^{1+}$, Sudesh Rathilal ${ }^{1}$, Kumnandi Pikwa ${ }^{1}$, Lingham Pillay ${ }^{2}$ \\ ${ }^{1}$ Faculty of Engineering and the Built Environment, Department of Chemical Engineering, Durban University of Technology, 4001 Berea, 70 Mansfield \\ Road. Durban, South Africa \\ ${ }^{2}$ Department of Process Engineering, Stellenbosch University, Private Bag X1 Matieland 7602, South Africa
}

\begin{abstract}
Current available commercial membranes are not robust and are therefore destroyed if left to dry out or handled roughly. Woven fibre microfiltration (WFMF) membranes have advantages over its competitors with respect to durability, thus, favourable for the developing economies and operation during rough conditions. Evaluation of the effects of aeration and brushing as a flux enhancement strategies for WFMF membrane was the purpose of this study. The WFMF membrane was found to be susceptible to pore plugging by colloidal material and adsorption/attachment by microbiological contaminants. This led to a $50 \%$ loss in flux. Aeration as a single flux enhancement strategy proved insufficient to maintain high flux successfully. Therefore combined flux enhancement strategies yielded the best results.
\end{abstract}

Keywords: Aeration, Flux enhancement, Fouling, POU, South Africa, Woven fibre membrane

\section{Introduction}

Wide application and research of membrane technology has vastly been carried out towards domestic waste water treatment and industrial waste water treatment. Streams from these sources are well researched and understood. They do not vary greatly from one plant/area to the other, thereby making waste water treatment facilities less troublesome to design, operate and even research. However, the raw water for drinking water treatment facilities differs from one area to the other and from one season to the other. Therefore, the plant design requirements for specific waters are different to others, even research findings are specific to the water studied [1, 2]. Lack of accurate information on the quality of the raw water to be used with the membrane at design stages has enhanced the risk of membrane fouling in drinking water treatment.

Lin et al. [3] and Sohrabi et al. [4] explained that membranes can increase the safety of water in two ways: firstly, they can be used at the consumption point as a tool for increasing security and secondly they can be part of the water purification system. With the use of alternative methods of water treatment, the gaps in the conventional (centralized) water treatment facilities can be covered. The use of membrane filtration process for the treatment of potable water at household levels is becoming attractive in recent times $[5,6]$. The superiorities of membrane technology over the conventional water treatment plants include but is not limited to; flexibility to upgrades and scaling, ability to handle varying incoming quality, small foot print plants, can be decentralized and centralized at will, can be easily incorporated into existing water treatment facilities and produce superior quality than most of the competing technologies [3, 7]. The advantages offered by membrane technology have made it suitable for rural communities where topographies are difficult and there is no infrastructure that conventional water treatment plants require [8].

Fouling is an irreversible alteration of a membrane due to specific physical and or chemical interactions between the membrane and various components present in the process stream. Membrane fouling manifests as a decline in filtrate flux and a change in membrane selectivity. The irreversible changes on the membrane that is due to fouling, continues throughout the process until extensive cleaning or replacement of the membrane is done [9].

Fouling of a membrane will arguably occur in two ways, namely
This is an Open Access article distributed under the terms of the Creative Commons Attribution Non-Commercial License (http://creativecommons.org/licenses/by-nc/3.0/) which permits unrestricted non-commercial use, distribution, and reproduction in any medium, provided the original work is properly cited.

Copyright (C) 2019 Korean Society of Environmental Engineers
Received May 2, 2018 Accepted October 11, 2018

${ }^{\dagger}$ Corresponding author

Email: mnchollom@gmail.com

Tel: +27-732663415

ORCID: 0000-0001-6345-4614 
macro solute adsorption (intermolecular interaction) and particle deposition (particle induced macro solute). These can take place progressively or simultaneously depending on the feed composition and membrane chemistry. It is the intermolecular forces between the membrane and solutes that governs membrane-solute interactions. These intermolecular interactions between the membrane and various components in the feed could be classed as quantum mechanical, electrostatic and polarization forces [9, 10].

Membrane fouling contributes to $80 \%$ of the operational and maintenance costs of membrane systems; this is even higher than the skills of the personnel operating membrane systems. Operation and maintenance cost of membrane systems could be higher than the capital costs of the system. Membrane fouling control deals mainly with the management or minimization of the effect of membrane fouling since fouling itself cannot be completely avoided in membrane filtration [11].

Membrane fouling can be controlled and managed at different stages. These are feed pre-treatment to limit its fouling propensity, improving the antifouling properties of the membrane, membrane cleaning and backwashing conditions and optimisation of operating conditions [12]. It is common that the feed characteristics and the membrane properties cannot be altered to mitigate fouling, leaving only operation conditions for fouling control and mitigations. Some of the operating conditions include, temperature, cross flow velocity, aeration, relaxing, back flushing/ backwashing, transmembrane pressure, membrane surface, etc.

Air scouring generates localized cross flow conditions along the membrane surface thereby reducing the deposition of particles and the development of a cake layer on the membrane surface. The same effect of shear induced diffusivity of the particles seen in cross flow velocity is achieved in immersed membrane systems but with air bubbles as the media to promote particle collision on the membrane surface. In immersed membrane systems when the air flow rate is increased, shear intensity on the membrane surface is increased and the fouling effects are reduced [13]. Similarly, it has been observed that increasing the aeration rate has a critical has a high limit on the membrane, running above which no fouling reduction is observed. The suspended solids and microbial flocs above the critical aeration rate break. When this happens, microbial flocs release EPS and the suspended solids are broken into fine high fouling particulates [14].

The woven fibre microfiltration (WFMF) membrane is a novel membrane that can be used both for the treatment of portable water and wastewater. The advantages that the WFMF has over other conventional membranes have been described elsewhere [15]. Most commercial membranes are susceptible to damage if not properly handled, however, the WFMF have the ability to withstand rough manhandling. The performance of the membrane for the treatment of portable water has been evaluated by [6]. The studies found that WFMF was capable of producing permeates with a turbidity below 1 NTU and as well it served as a multiple barrier against bacteria and protozoa. The final permeates were then easily disinfected with suitable disinfectants, thereby meeting the recommended WHO standards. Similarly, Alfa et al. [16] developed and evaluated the use of the WFMF as a small scale disinfection unit for water treatment. They found out that disinfection was affected by the turbidity of the water, hence the use of the WFMF aided in the removal of the turbidity. Chollom et al. [15] studied the effects of backwashing and brushing to mitigate fouling and the best cleaning options for the recovery of flux using synthetic feed. They found that a combination of fouling mitigation methods yielded the best results. This study is focused on evaluating the performance of the WFMF unit with respect to its fouling propensity to different feed samples and also to evaluate aeration as a flux enhancement strategy for the application of WFMF for water treatment.

\section{Materials and Methods}

\subsection{Collection of Samples}

Raw river water from Duzi/Umkomaasi and a synthetic feed was used for this study. Duzi and Umkomaasi River were found to be highly fouling on the WFMF membrane. The synthetic feed solution used in this study was prepared with Duzi River clay. Activated sludge from the aeration section was obtained from Northern Water Works wastewater treatment, Durban, South Africa. This wastewater treatment plant treats both domestic and industrial wastewater. The concentration of river clay in the synthetic feed was $3 \mathrm{~g} / \mathrm{L}$, and the activated sludge was maintained at $2 \%$ of the total volume of the synthetic feed solution. Activated sludge was used due to the presence of microorganisms in it. This was necessary for the evaluation of fouling due to microorganisms. The basic compositions of the feed solution are presented in Table 1. Three other feeds, clay solutions, $0.8 \mu \mathrm{m}$ calcium hydroxide solutions and $2 \mu \mathrm{m}$ calcium hydroxide solution were used for the fouling test. Calcium hydroxide solutions were prepared by dissolving $3.5 \mathrm{~g}$ of the $2 \mu \mathrm{m}$ and $0.8 \mu \mathrm{m}$ of calcium hydroxide in $1 \mathrm{~L}$ of tap water.

The size of the river clay particles were measured to be 0.4 $\pm 0.05 \mu \mathrm{m}$ using a modified size exclusion method (MSE). Details of the procedure have been elaborated elsewhere [10].

The final composition of the synthetic feed solution was arrived at using a trial and error method, so that its fouling profile on a clean membrane was similar to that of Duzi and Umkomaasi

Table 1. Characteristics of Feed Samples, the Synthetic Feed Was Made to Be of Similar Fouling Characteristics with the Local Rivers

\begin{tabular}{lcccc}
\hline & Units & Duzi River & Umkomaasi River & Synthetic feed \\
Turbidity & NTU & 80 & 120 & 200 \\
Colour & ${ }^{0} \mathrm{H}$ & 8.5 & 9.5 & 8.5 \\
Total coliforms & Count per $100 \mathrm{~m} \ell$ & 19,344 & 12,300 & 15,475 \\
E. coli & Count per $100 \mathrm{~m} \ell$ & 8,412 & 2,140 & 12,324 \\
\hline
\end{tabular}


River. The identified major foulants from Duzi and Umkomaasi River were colloidal matter and microbiological components. This was the reason clay and domestic sewerage was used in preparing the synthetic feed. The residual chlorine of the tap water in the feed tank was measured once a day and was maintained below $0.1 \mathrm{mg} / \mathrm{L}$. This was to ensure that microbiological deactivation does not occur in the feed tank.

\subsection{Membranes and Analytical Test}

Flat sheets from WFMF were used for this study. The membrane is a polyester based fibre locally sourced and was supplied by the Gelvenor Consolidated Fabrics PTY Ltd in Durban, South Africa. The pore size of the membrane was $0.45 \mu \mathrm{m}$ inferred from its similar separation abilities with a $0.45 \mu \mathrm{m}$ Millipore filter paper and a $0.45 \mu \mathrm{m}$ Kubuta membrane. A plate and frame module that was $500 \mathrm{~mm}$ in length and $300 \mathrm{~mm}$ in width was constructed on a $5 \mathrm{~mm}$ PVC frame. A wire mesh was inserted to enhance fluid flow between the membrane and the frame. The modules were packed together into a pack of 5 modules and were spaced $5 \mathrm{~mm}$ apart from each other. The pack was held together by four carbon steel rods that were inserted through the holes drilled on the membrane edges, and $5 \mathrm{~mm}$ nuts were used to separate these membrane modules. The total filtration area of the membranes was $1.5 \mathrm{~m}^{2}$. Figures demonstrating the membranes modules were reported by Alfa et al. [16]. Each membrane module had its individual permeate collection point outside the filtration tank. This was used for individual analysis and data verification. The thickness of the membrane material was $1.2 \mathrm{~mm}$ and was measured by a Vernier Calliper.

Turbidity test was carried out with the HACH 2100Q Portable Turbid meter. The standard method of using the turbidity meter was followed. E-coli and coliform tests were done according to the IDEXX Collilert reagent method. Total and free chlorine was tested using HACH new 5870000 Pocket Colorimeter.

\subsection{Gradient to Assess Flux Enhancement Strategies Performance}

Six different feed samples were analysed to evaluate their fouling characteristic. The samples used were Duzi River, Umkomaasi River, Synthetic feed, clay solution, $0.8 \mu \mathrm{m}$ lime solution and $2 \mu \mathrm{m}$ lime solution. The interaction between the foulants and membrane is a determining factor of the extent of membrane fouling, and therefore the reason for the selection of lime as one of the feed samples. The major foulants that were common in these two rivers were turbidity, suspended colloidal matter and microbiological components (coliforms and bacteria). $50 \mathrm{~L}$ feed was prepared for the experiment. The prepared feed was filtered with the membrane filtration cell driven by gravity as shown in Fig. 1. The synthetic feed flux profile was compared to the flux profiles of Duzi and Umkomaasi River. The composition of the synthetic feed was adjusted until the flux profile was similar to the profiles of the two rivers. The activated sludge was kept in the refrigerator at $10^{\circ} \mathrm{C}$ for a maximum of $5 \mathrm{~d}$. After which the unused sludge was discarded and fresh sludge was collected for subsequent feeds. The continuous use of the sludge was to ensure that the biological fouling characteristics of the microorganisms were always present in the prepared feed samples for the whole duration of the experiments.

The gradient was used to assess the rate of flux decline. A high value of the gradient indicated rapid decline in flux over filtration. The rapid decline in permeate flux was interpreted as high fouling of the WFMF membrane with filtration time. According to Shi et al. [11] flux decline in constant pressure driven systems occurs in three progressive steps; severe drop in flux, moderate drop in flux and very slow drop in flux. He referred to these steps as deposition and compaction steps, cake layer development and pseudo steady state. These stages are observed when no flux enhancement strategy is used. The effectiveness of the flux enhancement was calculated for the three progressive steps on the base case profile when filtering feed with

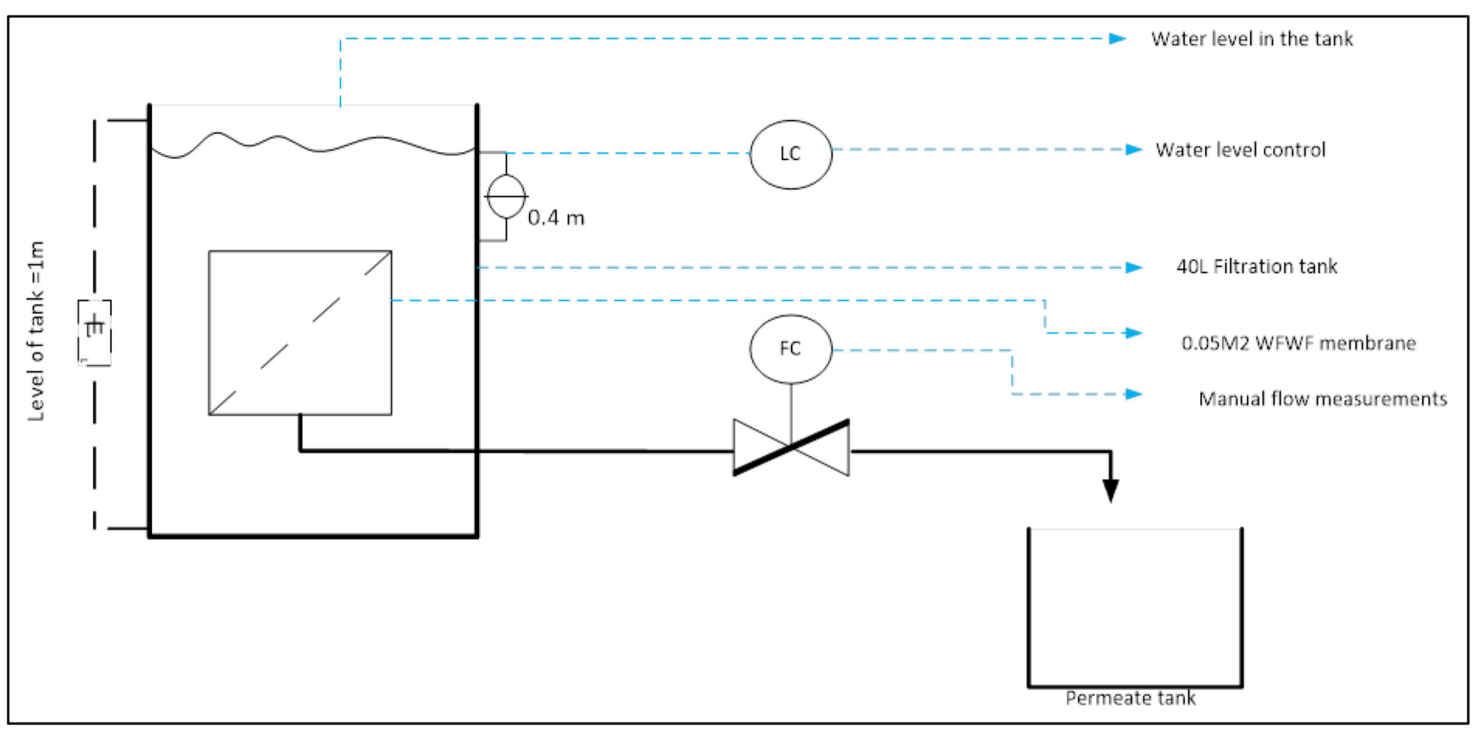

Fig. 1. Schematic flow diagram for fouling test on six samples to evaluate the fouling profile of the WFMF membrane. 


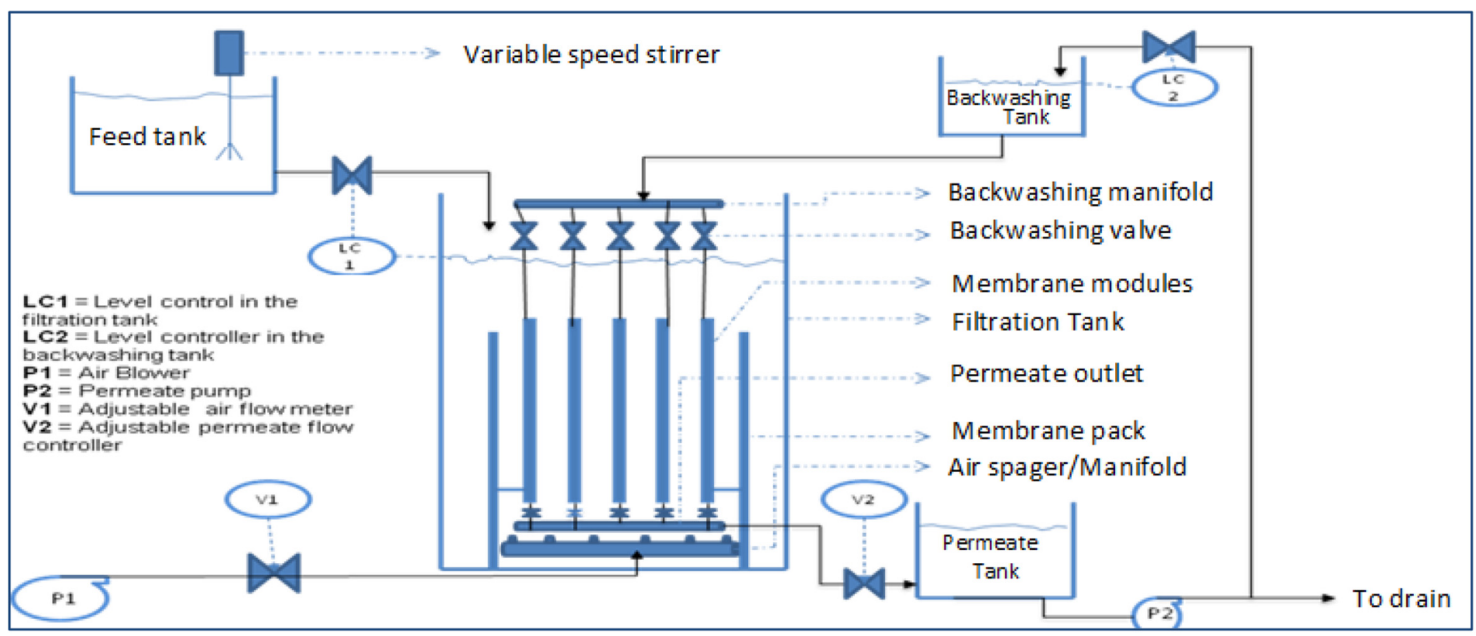

Fig. 2. Experimental set-up used for the evaluating the flux enhancing strategies.

the WFMF membrane. The obtained gradients were compared to the gradients calculated during aeration. In the same manner, the gradients were used to assess the effectiveness of cleaning/removing of the particles that restricted flux. The gradient of a clean WFMF membrane should be high at the initial stages of filtration. Eq. (1) was used to calculate flux decline in the membrane.

$$
\operatorname{Gradient}(\text { Flux decline })=\frac{J_{2}-J_{1}}{t_{2}-t_{1}}
$$

where $J_{2}$ is the flux taken at point 2 of the declining slope of flux and point $J_{1}$ is initial point or the proceeding point in the flux decline slope measured in LMH. $t_{2}$ is time 2 corresponding to $J_{2}$ and $t_{1}$ was the initial time corresponding to $J_{1}$.

In filtration, the overall gradient for pure water flux at constant pressure is zero because the flux is constant. The overall gradient for a highly fouling feed which has an almost vertical slope is infinity. The fluxes of both the cleaned membrane and fouled membranes were therefore used for the analysis. It was on these two extremes that the overall gradient assessment of flux enhancement strategies was used. The best flux enhancement strategy aeration was expected to a have a gradient that approaches the gradient of pure water in relation to the worst performing flux enhancement strategy. Overall gradient was also used to assess the effectiveness of cleaning or flux recovery. A clean membrane is expected to have a high gradient because of high filtration rate. Therefore, the fouled membrane fluxes were compared to the flux of the cleaned membrane. This was found to be an effective way to assess the success of the flux enhancement strategy. A detailed description of on how the WFMF were backwashed and brushed has been elaborated in [17].

The base case profile was used to measure the decline in flux. It indicates the lowest flux possible for a specific feed, WFMF membrane and operating conditions. Two external membranes in the membrane pack were used to plot the base case curve. These two membranes were isolated from aeration. The further away the flux was from the base case curve when employing aeration, the more it was deemed successful. The larger the difference between the base case flux and the flux obtained during aeration meant better performance. The differences were calculated on a daily basis as well as an overall flux after the experiments.

$$
\% \text { flux improvement }=\left(\frac{J_{o}-J_{f}}{J_{o}}\right) 100
$$

Where $J_{0}$ is the average flux for the base case (no flux enhancement is employed) in LMH, $J_{f}$ is the average flux for the enhanced flux in $\mathrm{LMH}$.

\subsection{Effect of Aeration}

Aeration in submerged membrane systems is intended to create turbulence at the membrane surface which minimizes the accumulation of fouling particles on the membrane surface. The membrane scouring air was supplied by the air blower as shown in Fig. 2. The air flow rate was varied as 10,20 and $30 \mathrm{~L} / \mathrm{min}$ to study the effect of scouring rate on fouling minimization. The aeration rate reported was based on the performance of each module, and not the whole pack of five modules. The perforations on the air diffuser were $0.5 \mathrm{~mm}$ and the membrane spacing was $0.5 \mathrm{~cm}$. Aeration was continuous throughout the filtration period at a steady air flow rate. Baffles in between the membranes were inserted to ensure that air does not escape to the space where the bubbles will not make contact with the membrane. The starting point of the aeration rate was adopted from available data which is based on the economically used values in MBRs [18].

\subsection{Effect of Membrane Brushing}

WFMF membrane brushing was done in-situ and the duration of brushing was 1 min per membrane side. WFMF membrane brushing was done by inserting a bottle brush in between the membranes. Contact was made with only the membrane module being targeted for brushing. Membrane brushing involved applying pressure by the brush on the membrane being brushed and the brush was moved randomly in all directions. During membrane 
brushing, filtration on that specific membrane was stopped by shutting the isolation valve at the bottom of the membrane module. Upon completion of one side of the membrane module, the next was brushed as well. Brushing cycles were varied at frequencies of 3,6 and $12 \mathrm{~h}$ and the brushing duration was varied at 20, 30 and $60 \mathrm{~s}$ per module side (120 s per module).

\section{Results and Discussion}

\subsection{Fouling Characteristics and Profile for the Feed Samples}

Fig. 3 shows the fouling characteristics of the feed samples. The purpose of the experiment was to demonstrate the effects of different feed samples on the fouling of the WFMF membrane.

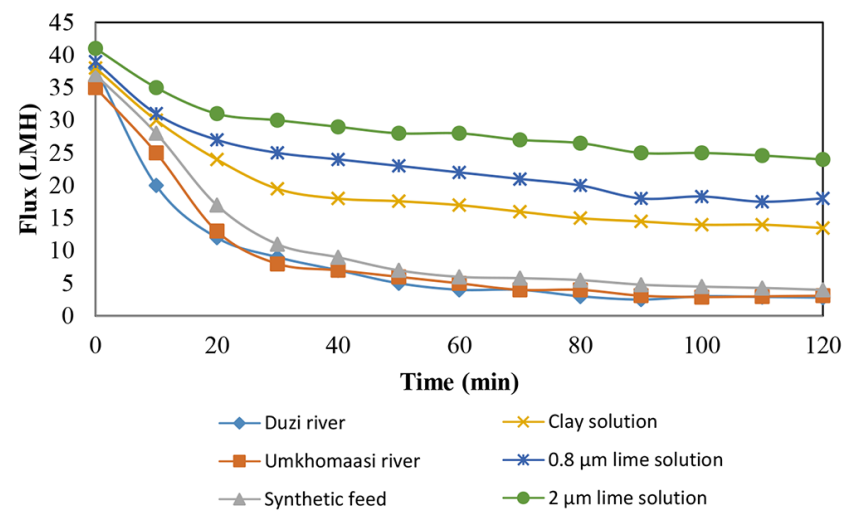

Fig. 3. Fouling profile for different feeds on the WFMF membrane.
The flux profile obtained during filtration of six different samples, Duzi River, Umkomaasi River, synthetic feed, $3.5 \mathrm{~g} / \mathrm{L}$ of clay solution, $3.5 \mathrm{~g} / \mathrm{L}$ of $0.8 \mu \mathrm{m}$ lime solution and $3.5 \mathrm{~g} / \mathrm{L}$ of 2 $\mu \mathrm{m}$ lime solution. The results show that three samples had the highest flux decline, these were Duzi River, Umkomaasi River and synthetic feed. $2 \mu \mathrm{m}$ lime solution had the lowest decline in flux followed by $0.8 \mu \mathrm{m}$ lime solution and lastly clay solution. The three samples with the highest flux decline rate had microbial components which was absent in the other feed samples. The high rate of fouling was therefore assumed to be due to the microbial components. The microbiological components as shown in Table 1 were represented as total coliforms and E. coli. According to Yamamura et al [8] and Abdelrasoul et al. [13] microbiological, bacterial and organic foulants mostly foul membranes by attaching on the membrane surface and adsorbing onto the membrane surface. The samples with less flux decline were single component solutions of lime and clay solutions. The differences amongst these single component samples were the particle sizes of the components, which were $0.8 \mu \mathrm{m}$ lime, $2 \mu \mathrm{m}$ lime and \pm 0.45 $\mu \mathrm{m}$ clay. Clay particle size is discussed in the next section.

Observable also from Fig. 3 is that the flux decline in all six samples progressed in three distinctive steps, particularly for the three highly fouling samples. There was a sharp decline for the first 20 min which was followed by a short medium decline which also lasted for $20 \mathrm{~min}$ and the last step was a slow decline which continued for the rest of the filtration period. Zhang et al. [19] describes these steps as the deposition and compaction steps, cake layer development and pseudo steady state. The rate of flux decline during these three steps was assessed by the gradient line and the results are shown in Table 2 .

Table 2. Gradient Assessment of Flux Decline during WFMF Membrane Filtration

\begin{tabular}{|c|c|c|c|c|c|c|}
\hline Progressive fouling steps & $\begin{array}{l}\text { Duzi } \\
\text { River }\end{array}$ & $\begin{array}{c}\text { Umkomaasi } \\
\text { River }\end{array}$ & $\begin{array}{c}\text { Synthetic } \\
\text { feed }\end{array}$ & $\begin{array}{c}\text { Clay } \\
\text { solution }\end{array}$ & $\begin{array}{l}0.8 \mu \mathrm{m} \text { lime } \\
\text { solution }\end{array}$ & $\begin{array}{c}2 \mu \mathrm{m} \text { lime } \\
\text { solution }\end{array}$ \\
\hline Deposition gradient (LHM/min) & -1.30 & -1.10 & -1.01 & -0.70 & -0.60 & -0.50 \\
\hline Cake layer development gradient (LMH/min) & -0.25 & -0.30 & -0.40 & -0.30 & -0.15 & -0.10 \\
\hline Pseudo steady state gradient (LMH/min) & -0.05 & -0.05 & -0.06 & -0.06 & -0.08 & -0.06 \\
\hline Overall gradient (LMH/min) & -0.29 & -0.29 & -0.28 & -0.20 & -0.17 & -0.12 \\
\hline
\end{tabular}
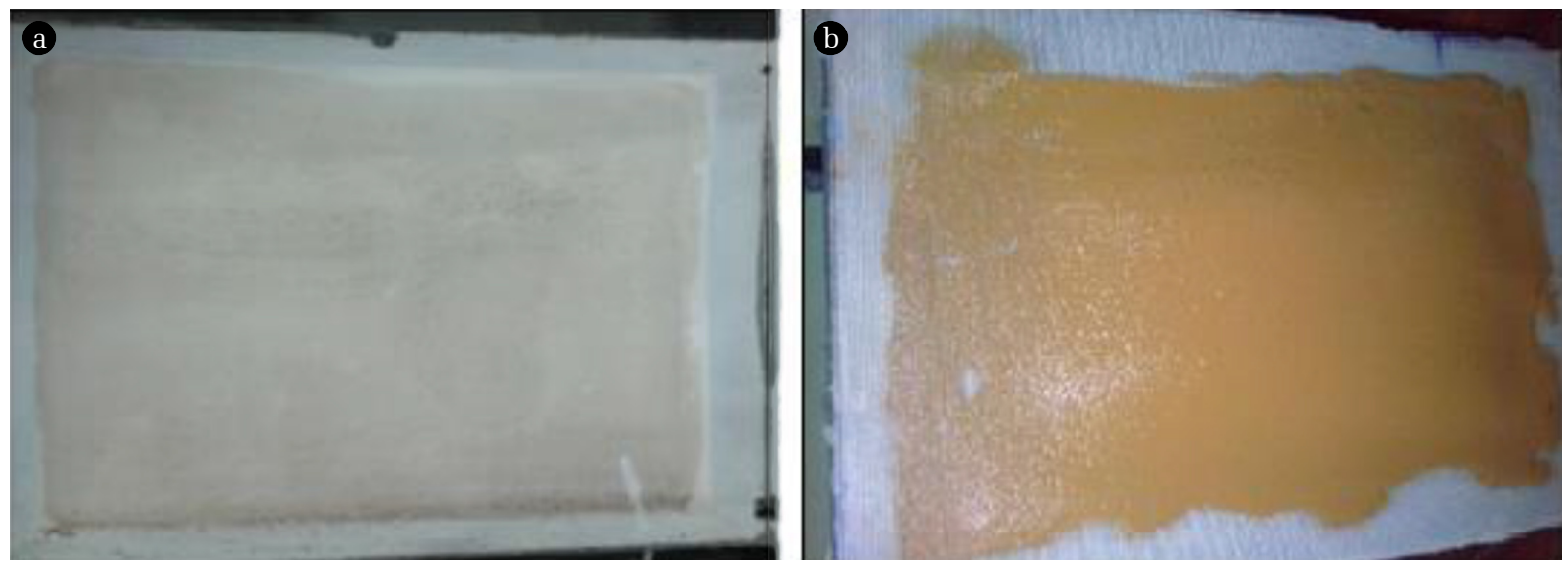

Fig. 4. Picture of WFMF membrane after 20 min of filtration (a) left and for the entire period (b) right. 
The results shown in Table 2 confirm the trend shown in Fig. 4. The highest decline in flux for all the samples occurred in the first $20 \mathrm{~min}$ (deposition and compaction step). The multi-component feed samples (Duzi, Umkomaasi and synthetic feeds) had a flux decline rate which was greater than $1 \mathrm{LMH} / \mathrm{min}$. This lasted only for $20 \mathrm{~min}$. While the single component feed samples had a flux decline rate during the same period which was less than $1 \mathrm{LMH} / \mathrm{min}$. The interesting observation from the results in Table 2 is the close proximity of the cake layer development step gradient and the overall gradient. The overall gradient tells the fouling rate of the sample on a WFMF membrane for the entire duration of the experiment. The similarities of the overall gradient and the cake development gradient could mean that the big gradient during deposition and compaction is offset by the small gradient during the pseudo steady state stage.

To assess whether there was any cake development during the deposition and compaction stage of filtration, which could contribute to the high flux decline during this stage, the WFMF membrane during synthetic feed filtration was taken out of the filtration tank to observe the membrane surface. Fig. 4(a) and (b) shows a visual representation of the WFMF membrane in the first $20 \mathrm{~min}$ of filtration for the synthetic feed solution. Fig. 4(b) shows a visual representation of the WFMF membrane after the entire filtration period. Fig. 4(a) shows that very little development of the cake layer occurred on the WFMF membrane during the first $20 \mathrm{~min}$ of filtration when it is compared to the fully developed cake layer on the WFMF membrane as shown in Fig. 4(b). The observation in Fig. 5 implies that deposition on the WFMF membrane that resulted in a high decline in flux could have occurred on the WFMF membrane internals rather than on the surface.

\subsection{Flux Enhancement Strategy}

For each experiment, a base line fouling curve was done in conjunction with the flux enhancement strategy used for comparison between the flux enhancement strategy used and the fouling curve.

\subsubsection{Effect of aeration}

The effects of air scouring on the WFMF membrane was investigated in order to maintain high flux. The results are shown in Fig. 5. It shows that air scouring of the WFMF membrane improves its flux. The aeration rate reported was per module.

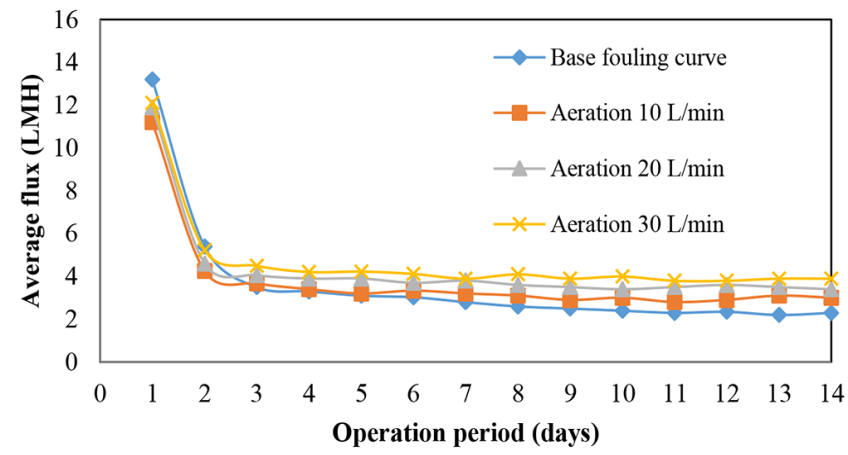

Fig. 5. Effect of aeration on flux enhancement. Increasing the aeration rate improved the permeate fluxes of the membrane.
Increasing the aeration rate had a positive impact on flux. Aeration rate of $10 \mathrm{~L} / \mathrm{min} . \mathrm{m}^{2}$ improved the flux by $11 \%$, aeration of 20 and $30 \mathrm{~L} / \mathrm{min}$ had an improvement of $25 \%$ and $36 \%$, respectively. The average flux improvement was calculated using Eq. (2), where the improvement is from the base case average to the enhance flux average.

The gradient/rate of flux decline for the period of $14 \mathrm{~d}$ was $0.29 \mathrm{LMH} / \mathrm{d}$ without aeration. When the WFMF membrane was aerated at a rate of $10 \mathrm{~L} / \mathrm{min}$ the gradient was reduced to 0.23 $\mathrm{LMH} / \mathrm{d}$, this was further improved to 0.21 and $0.20 \mathrm{LHM} / \mathrm{d}$ for 20 and $30 \mathrm{~L} / \mathrm{min}$, respectively.

Fig. 6 shows the fouled membranes as seen visually on the effect of aeration rate. Without aeration a thick slimy cake layer on the surface of the membrane is seen and the thickness and the visibility of the cake layer is reduced as aeration rate is increased.

The reason for improved flux when aeration rate is increased lies in the effectiveness to remove the accumulated particles from the membrane surface. The aeration rate of $30 \mathrm{~L} / \mathrm{min}$ is more effective to remove the accumulated particles on the membrane surface than the aeration rate of $10 \mathrm{~L} / \mathrm{min}$. The reason being that at the high aeration rate of $30 \mathrm{~L} / \mathrm{min}$, there was no significant visible cake layer on the surface of the membrane as compared to the membrane aerated at a rate of $10 \mathrm{~L} / \mathrm{min}$. Therefore the high aeration rate of $30 \mathrm{~L} / \mathrm{min}$ is more effective in controlling and even eliminating cake build up on the WFMF membrane, but the success only contributes a maximum of $36 \%$ in flux improvement. A flux improvement of only $36 \%$ at a high aeration of $30 \mathrm{~L} / \mathrm{min}$ was not expected because much higher fluxes have been reported in MBR systems [13]. However, this could be explained by the differences in particle sizes in the feed solutions. Particle sizes of the flocs in MBRs can be up to 20 times bigger than the membrane pore size.

The WFMF membrane has shown not to have a flat smooth surface, but has trenches and troughs as the fibres are twisted and weaved into a uniform pattern [15], and therefore the reason for the $36 \%$ improvement in flux at such a high aeration rate. It is in these trenches that the expected fine particles in a solution get stuck and block the membrane pores and results in a decline in flux even at high aeration rates. Even in between the fibres, the fine particles are expected to get in there and hinder permeate flow. The air bubbles from air scouring cannot get to these trenches and if the fine air bubbles produced during aeration do get into the trenches they do not have the necessary force to remove the trapped clay particles.

The clay particles were averaging $0.4 \mu \mathrm{m}$ in diameter against the membrane pore size of about $0.45 \mu \mathrm{m}$ and a thickness of $1.2 \mathrm{~mm}$. The size of the clay particles in relation to the WFMF membrane pore size is similar. It is therefore credible that the particles could get into the membrane pores and get stuck inside the pore channel and trenches. Air bubbles cannot impact these particles. They therefore block permeate path and the net result is a reduction in flux. Cross flow velocity is not effective in dispersing fine particles away from the membrane surface and eventually into the membrane pore. This is a common finding amongst membrane researchers such as [20, 21]. 

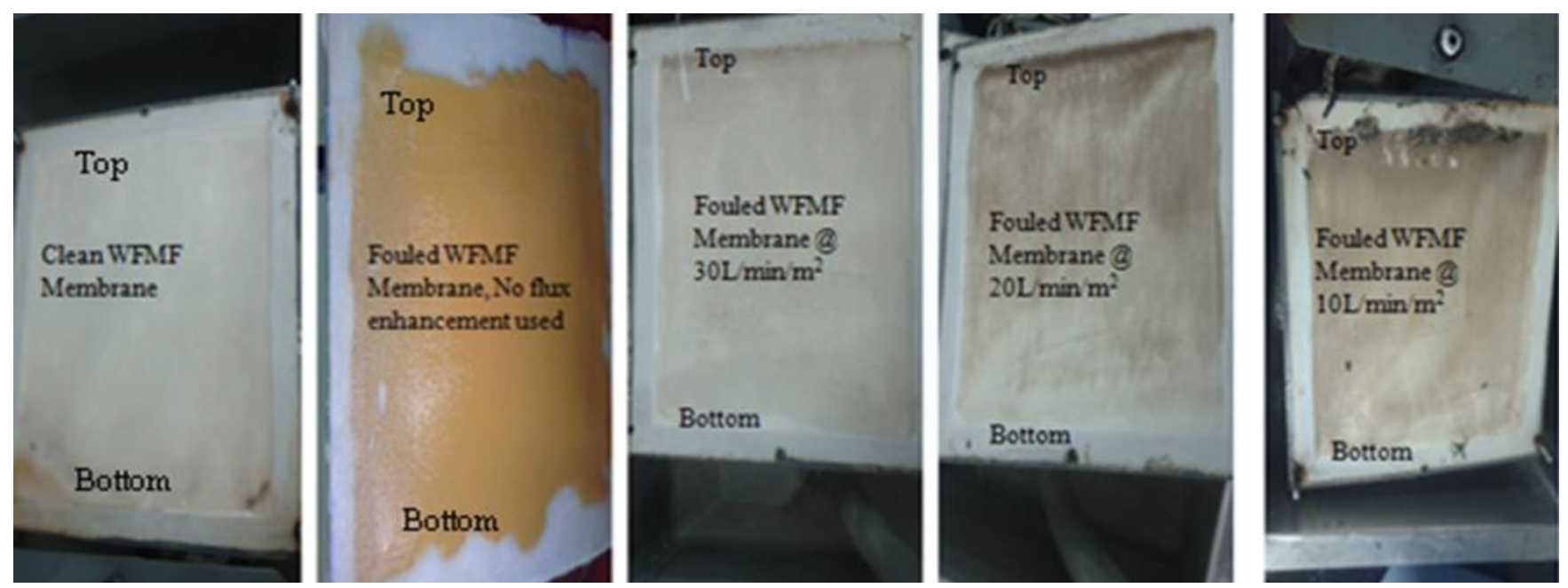

Fig. 6. Photos of fouled membranes at different aeration rates, the second membrane from the left is a fouled membrane without aeration.

The WFMF membrane is prone to adsorption fouling with the synthetic feed. Because adsorption fouling occurs on contact between the macromolecular protein-like foulants present in the feed solution, aeration was not effective in controlling this type of fouling. Air scoring is effective in controlling the build-up of a cake layer on the surface of the WFMF membrane at a maximum achievable aeration rate of $30 \mathrm{~L} / \mathrm{min}$. Controlling the cake build up contributed to a $36 \%$ improvement flux. This finding implied that there are other fouling mechanisms that caused a decline in flux on the WFMF membrane other than cake layer build up on the membrane surface which cannot be controlled by air scouring. Therefore based on the results in Table 2, it was assumed that the WFMF membrane fouled by pore blocking and constriction and adsorption fouling. A combination of these two fouling mechanisms contributed to high fouling rate/high flux decline observed on the WFMF membrane.

\subsubsection{Optimisation of in-situ brushing}

Fig. 7 shows that when the brushing time is increased from 20 $\mathrm{s}$ to $30 \mathrm{~s}$ and finally to $60 \mathrm{~s}$ per module side, the flux decline is reduced and higher flux averages are obtained.

The increase in average flux reduction in the flux decline with the brushing time was observed to be due to the following; at

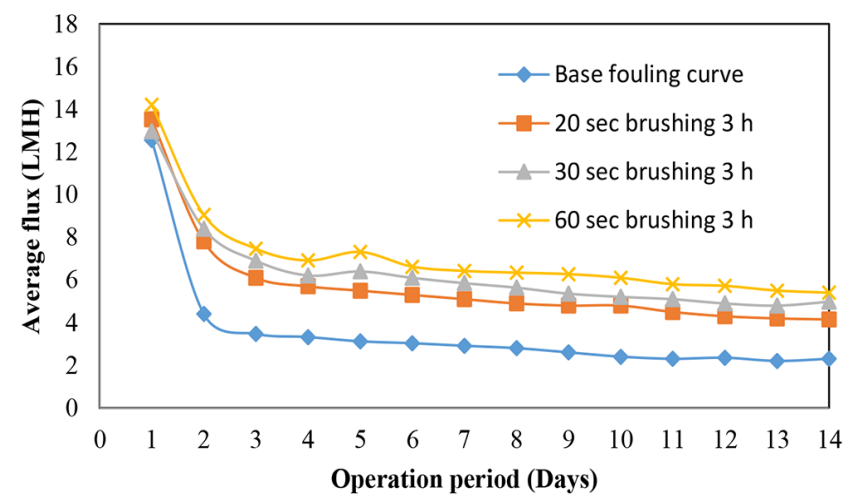

Fig. 7. In-situ brushing optimization profile at $3 \mathrm{~h}$ interval. longer brushing time, more of the attached particles were removed, the reason been that sufficient time for contact between the fouled membrane and the brush is allowed, thus enhancing more particles been removed. Brushing loosens the agglomerated particles due to the van de Waal forces. These reasons were believed to be the cause of the increase in average flux when the brushing time is increased. Therefore, $60 \mathrm{~s}$ brushing was found to be the best brushing time for the WFMF membrane. Increasing the brushing above $60 \mathrm{~s}$ was not studied because of its impracticality for larger systems with numerous membranes.

WFMF membrane was found to be prone to both internal and external fouling, therefore a single flux enhancement strategy that deals with either internal fouling or external fouling could not be completely effective in flux enhancement. The effect of brushing the WFMF membranes in-situ in between filtration cycles on flux improvement is shown in Fig. 8. In-situ brushing is not common in submerged systems but can be a practical flux enhancement strategy for small scale systems. Each WFMF membrane was brushed for $1 \mathrm{~min}$ by inserting the brush in between the membrane.

The effect of the brushing frequency is clearly indicated as seen in the average flux increase (Fig. 9). The improvement in flux was calculated to be $87.3 \%, 55.9 \%$ and $28.7 \%$ for 3,6 and

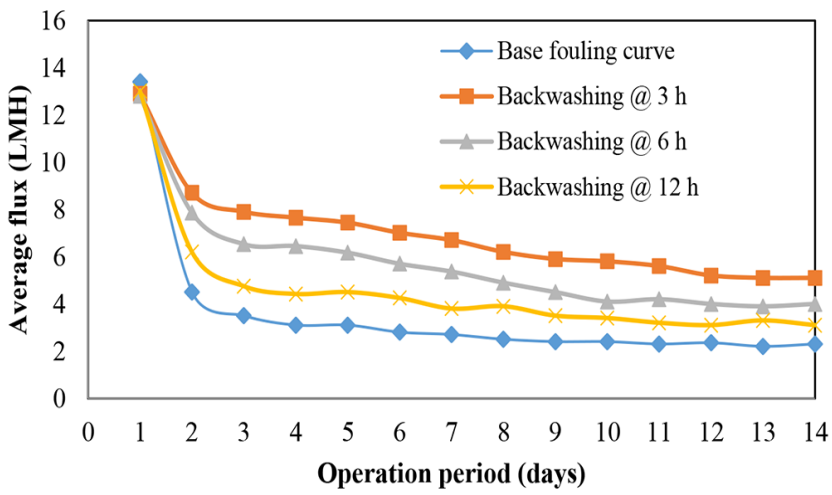

Fig. 8. The results of varying the brushing cycle on flux improvement for the WFMF membrane. 
Table 3. Effect of Brushing on Flux Recovery, Base Flux, Lost Flux and Gradient

\begin{tabular}{cccc}
\hline Brushing frequency (h) & Average recovery flux $(\mathbf{L M H})$ & Average base flux (LMH) & Average gradient per brushing cycle \\
\hline 3 & 11.72 & 6.1 & -2.78 \\
6 & 11.35 & 3.8 & -2.87 \\
12 & 10.1 & 3.2 & -3.2 \\
\hline
\end{tabular}

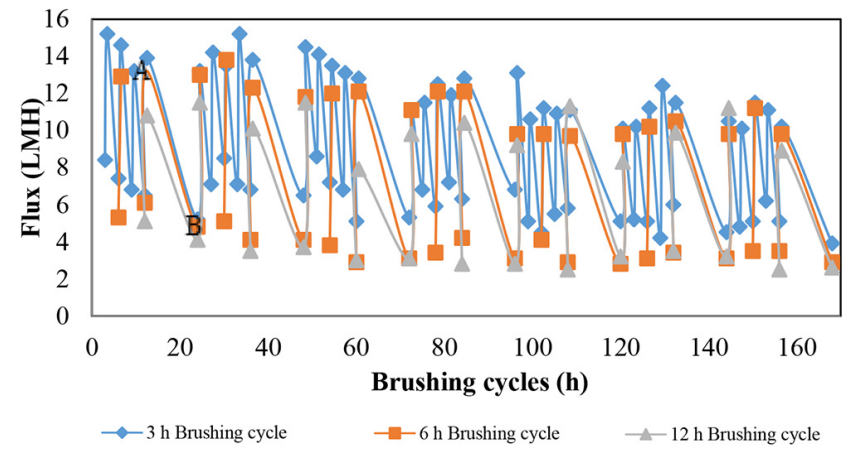

Fig. 9. In-situ brushing profile and flux recovery.

$12 \mathrm{~h}$ cycle of WFMF membrane brushing, respectively. The WFMF membrane brushing was intended to remove the fouling layer on the membrane surface. The improvement in flux implies that periodic brushing of the WFMF membrane had an impact on flux although it was for a short time.

Fig. 9 shows flux recovery after every brushing sequence. It can be seen that there was not much difference in the recovered flux between the 3 and $6 \mathrm{~h}$ brushing cycles. The $12 \mathrm{~h}$ cycles brushing had a lower flux recovery than the other two at start but towards the end of the filtration period the flux recovery for all three cycles were similar. At the high frequency brushing, an improvement in the flux was observed, this was attributed to the quick brushing before the flux dropped too low for the $3 \mathrm{~h}$ brushing cycle. This helped maintain a high average filtration flux for both 3 and $6 \mathrm{~h}$ brushing cycles.

To assess how long the recovered flux by brushing was maintained, a gradient on each of the brushing cycles was done. High gradients would mean the high fluxes are short lived before fouling settles in again. The results are tabled in Table 3.

The high gradients seen in Table 3 attest to the fact that the fouling layer on the WFMF membrane was being removed, but it was quickly re-establishing again on the membrane surface. The average gradient per backwashing cycle was calculated within the single cycle as shown by A and B in Fig. 9 and the equation used was Eq. (1). Particle deposition started once filtration had recommenced and was the reason for the high gradient as seen in Table 3. This sudden decline in flux was then attributed to adsorption fouling. This was derived from the fact that the fouling on the WFMF membrane after brushing was re-established too quickly according to the results in Table 3 .

Adsorption fouling occurs on contact with adsorptive materials, so when the cake layer on the membrane surface was removed by brushing, the adsorptive materials gained access to the WFMF membrane surface which was originally shielded by the cake layer. This explains the high gradients after membrane brushing, this is in agreement with a study by Field [21].

Even though membrane brushing was not continuous, a direct contact was made between the membrane and the brush with much force applied. This then made the shear achieved during brushing to be greater. As a result a high instantaneous flux after brushing resulted in high average fluxes. Membrane brushing had access to the trenches on the surface of the WFMF membrane. This also helped remove hidden fouling layers in the trenches which would have contributed to the membrane filtration area loss during filtration if not removed.

Periodic brushing helps in de-stabilising the adsorption fouling on the WFMF membrane. This instability created on the adsorption fouling helps to loosen the fouling making the membrane permeable to fluid flow and the net result was the improvement in flux. The decline in the average flux profile obtained during periodic brushing is an indicator that irreversible fouling could be growing on the WFMF membrane and could be as a result of periodically exposing the membrane to adsorption fouling after every brushing.

\section{Conclusions}

This study was focused on evaluating the performance of the WFMF unit with respect to its fouling propensity to different feed samples and also to evaluate flux enhancement strategy for the application of WFMF for water treatment. The WFMF membrane was found to be susceptible to pore plugging by colloidal material and adsorption/attachment by microbiological contaminants. This led to a $50 \%$ loss in flux. It was found that air scoring was not as effective in controlling the build-up of a cake layer on the surface of the WFMF membrane, because the major fouling of the WFMF membrane was due to internal fouling. The physical structure of the WFMF membrane (thickness, surface view and pore size) was a major factor that caused aeration to be ineffective in flux control. Brushing of the membranes at 60 $\mathrm{s}$ as an alternative to aeration provided a higher flux.

\section{Acknowledgments}

The authors wish to thank the Durban University of Technology and the National research foundation for providing $\mathrm{PhD}$ scholarship.

\section{References}

1. Liu G, Zhang Y, Knibbe WJ, et al. Potential impacts of changing 
supply-water quality on drinking water distribution: A review. Water Res. 2017;116:135-148.

2. Cheremisinoff NP. Handbook of water and wastewater treatment technologies. 3rd ed. USA: Butterworth Heinemann; 2002. p. 335-367.

3. Lin T, Shen B, Chen W, Zhang X. Interaction mechanisms associated with organic colloid fouling of ultrafiltration membrane in a drinking water treatment system. Desalination 2014;332:100-108.

4. Sohrabi MR, Madaeni SS, Khosravi M, Ghaedi AM. Chemical cleaning of reverse osmosis and nanofiltration membranes fouled by licorice aqueous solutions. Desalination 2011;267: 93-100.

5. Chew CM, Aroua MK, Hussain MA, Ismail WMZW. Evaluation of ultrafiltration and conventional water treatment systems for sustainable development: An industrial scale case study. J. Clean. Prod. 2016;112:3152-3163.

6. Mecha AC, Otieno FAO, Pillay VL. Long-term disinfection performance of silver nanoparticles impregnated membranes. Desalin. Water Treat. 2016;57:4906-4912.

7. Peter-Varbanets M, Zurbrugg C, Swartz C, Pronk W. Decentralized systems for potable water and the potential of membrane technology. Water Res. 2009;43:245-265.

8. Yamamura H, Okimoto K, Kimura K, Watanabe Y. Hydrophilic fraction of natural organic matter causing irreversible fouling of microfiltration and ultrafiltration membranes. Water Res. 2014;54:123-136.

9. Gao W, Liang H, Ma J, et al. Membrane fouling control in ultrafiltration technology for drinking water production: A review. Desalination 2011;272:1-8.

10. Ao L, Liu W, Zhao L, Wang W. Membrane fouling in ultrafiltration of natural water after pretreatment to different extents. J. Environ. Sci. (China) 2016;43:234-243.

11. Shi X, Tal G, Hankins NP, Gitis V. Fouling and cleaning of ultrafiltration membranes: A review. J. Water Process Eng.
2014;1:121-138.

12. Franken ACM. Prevention and control of membrane fouling: Practical implications and examining recent innovations. Membraan Applicatie Centrum Twente b.v.; 2009

13. Abdelrasoul A, Doan H, Lohi A. Fouling in membrane filtration and remediation methods. In: Nakajima $\mathrm{H}$, ed. Mass transfer - Advances in sustainable energy and environment oriented numerical modeling. Rijeka; Intech; 2013. p. 206-214.

14. Delgado S, Villarroel R, González E. Effect of the shear intensity on fouling in submerged membrane bioreactor for wastewater treatment. J. Membr. Sci. 2008;311:173-181.

15. Chollom MN, Pikwa K, Rathilal S, Pillay VL. Fouling mitigation on a woven fibre microfiltration membrane for the treatment of raw water. South Afr. J. Chem. Eng. 2017;23:1-9.

16. Alfa D, Rathilal S, Pillay VL, Pikwa K, Chollom MN Development and evaluation of a small scale water disinfection system. Water Sanit. Hyg. Dev. 2016;6:389-400.

17. Pikwa K, Rathilal S, Pillay VL. Development and evaluation of flux enhancement and cleaning strategies of woven fibre microfiltration membranes for raw water treatment in drinking water production [dissertation]. Durban, South Africa: Durban Univ. of Technology; 2015.

18. Kazemzadeh-Afshar M, Sarrafzadeh M-H, Mehrnia M-R. Performance of an airlift membrane bioreactor under different aeration rates. J. Membr. Sep. Technol. 2012;1:145-154.

19. Zhang J, Chua HC, Zhou J, Fane AG. Factors affecting the membrane performance in submerged membrane bioreactors. J. Membr. Sci. 2006;284:54-66.

20. Pradhan M, Vigneswaran S, Kandasamy J, Aim RB. Combined effect of air and mechanical scouring of membranes for fouling reduction in submerged membrane reactor. Desalination 2012;288:58-65.

21. Field R. Fundamentals of fouling. In: Peinemann K-V, Nunes SP, eds. Membrane technology, membranes for water treatment. Weinheim: WILEY-VCH; 2010. p. 1-23. 